Paidéia, 2002, 12(23), 57-75

\title{
INTELIGÊNCIA FLUIDA: DEFINIÇÃO FATORIAL, COGNITIVA E NEUROPSICOLÓGICA ${ }^{1}$
}

\author{
Ricardo Primi ${ }^{2}$ \\ LabAPE - Universidade São Francisco
}

\begin{abstract}
RESUMO: Este artigo pretende revisar o construto inteligência fluida $(G f)$ buscando ressaltar os pontos de convergência entre eles. Discute-se alguns estudos relevantes das abordagens psicométrica, cognitiva e da mais recente neurociência cognitiva. A tendência corrente é associar a inteligência fluida a pelo menos sete funções do executivo central, componente da memória de trabalho: (a) manutenção do nível de ativação das representações mentais, (b) coordenação de atividades mentais simultâneas, (c) monitoramento e supervisão das atividades mentais, (d) controle da atenção e atenção seletiva, (e) ativação dé informações da memória de longo prazo e (e) redirecionamento de rotas ou flexibilidade adaptativa. Discute-se também como os testes de raciocínio indutivo com analogias geométricas representam este construto.
\end{abstract}

Palavras-chave: executivo central, memória de trabalho, raciocínio indutivo, avaliação da inteligência, neuropsicologia, neurociência cognitiva.

\section{FLUID INTELLIGENCE: FACTORIAL, COGNITIVE AND NEUROPSYCHOLOGICAL DEFINITION}

\begin{abstract}
This paper reviews the construct fluid intelligence (Gf) with the intent to focus on the conceptual points of convergence among them. It was discussed some relevant studies from the psychometric, cognitive and the more recent cognitive neuroscience traditions. The current trend is to link fluid intelligence to at least seven functions of central executive component of working memory: (a) the level of activation maintenance of mental representations, (b) coordination of simultaneous mental activities, (c) monitoring and supervision of mental activities (d) attention control and selective attention, (e) activation of information from long-term memory (f) rerouting or adaptive flexibility. It was also discussed how geometric inductive reasoning tasks represent the construct $G f$.
\end{abstract}

Key-words: central executive, working memory, inductive reasoning, intelligence assessment, neuropsychology, cognitive neuroscience.

A inteligência humana talvez seja um dos assuntos mais estudados em toda a história da Psicologia. Para se ter uma idéia, uma busca feita no banco de dados PsycINFO da Associação Americana de Psicologia por artigos cujos títulos continham uma das palavras Intelligence, ou Intelectual ou Ability resultou em 18448 artigos desde 1887. Diante da imensidão de trabalhos publicados podemos conje-

\footnotetext{
'Artigo recebido para publicação em janeiro de 2002; aceito em março de 2002

2Endereço para correspondência: Ricardo Primi, Laboratório de Avaliação Psicológica e Educacional - LabAPE, Programa de Estudos Pós-Graduados em Psicologia, Universidade São Francisco, Rua Alexandre Rodrigues Barbosa, 45, CEP 13251-900, E-mail: rprimi@uol.com.br
}

turar que dificilmente existirá uma teoria consensual sobre o que é inteligência. De fato as teorias variam em razão da tradição de pesquisa herdada pelo estudo podendo ser classificada de modo geral em três grandes abordagens: a fatorial ou psicométrica, a desenvolvimentalista e a cognitiva (Almeida, 1988, 1994; Sternberg, 1979, 1980, 1981). Entretanto revisando os estudos podemos observar focos de consenso a despeito da imensidão de idéias, dados e modelos tratando do assunto. Neste artigo pretendese revisar um conjunto de estudos tratando do raciocínio ou inteligência fluida, como atualmente têm sido chamada, buscando ressaltar os pontos de convergência entre eles. $\mathrm{O}$ texto está dividido em três 


\section{Ricardo Primi}

grandes partes ligadas às abordagens: a primeira revisando a concepção psicométrica, a segunda trazendo alguns estudos clássicos da psicologia cognitiva e a terceira revisando alguns estudos mais recentes da neurociência cognitiva. Nesta última parte tentou-se resumir as funções cognitivas associadas à inteligência fluida e discutir como os testes de raciocínio indutivo representam este construto.

\section{Psicometria e Inteligência Fluida}

Dentro da tradição psicométrica parece haver um consenso quanto à existência de pelo menos oito fatores amplos subjacentes aos testes cognitivos (Flanagan, McGrew \& Ortiz, 2000; Flanagan \& Ortiz, 2001; Horn \& Noll, 1997). Este consenso foi solidificado a partir da publicação em 1993 do livro de John B. Carroll Human Cognitive Abilities: a survey of factor analytic studies. Neste estudo Carroll fez uma varredura dos últimos 60 anos na literatura científica, selecionou 461 conjuntos de dados de 1500 referências nas quais estavam incluídos quase todos os mais importantes e clássicos estudos da estrutura da inteligência feitos pela abordagem fatorial e efetuou uma reanálise utilizando métodos mais avançados. Este estudo resultou em um modelo hierárquico da inteligência chamado Teoria dos Três Estratos. $\mathrm{O}$ nome "Estrato" refere-se à idéia de camadas dispostas em três níveis em função da generalidade. O Estrato I contém pouco mais de 65 fatores específicos ligados ao formato dos problemas cognitivos propostos pelos testes psicométricos. O Estrato II agrupa estes fatores específicos em oito fatores mais amplos nos domínios do raciocínio, conhecimentolinguagem, memória-aprendizagem, percepção visual, percepção auditiva, produção de idéias, velocidade de processamento cognitivo e velocidade de decisão. O Estrato III corresponde ao fator $g$ de Spearman indicando a existência de operações cognitivas comuns a todas as atividades mentais

O modelo é semelhante à concepção moderna da teoria $G f-G c$ (inteligência fluida e cristalizada) iniciada por Cattell $(1941,1971)$ e desenvolvida e aprimorada por Horn (1991), Horn e Cattell (1966) um de seus estudantes. McGrew e Flanagan (1998) propuseram uma integração das teorias $G f-G c$ e dos Três Estrados criando-se a Teoria de Cattell-HornCarroll - $\mathrm{CHC}$ das Habilidades Cognitivas resultan- do em uma visão hierárquica multidimensional da inteligência organizando-a em dez fatores amplos (inteligência fluida, conhecimento quantitativo, inteligência cristalizada, leitura e escrita, memória de curto prazo, processamento visual, processamento auditivo, armazenamento e recuperação da memória de longo prazo, velocidade de processamento, rapidez de decisão) e pouco mais de sessenta fatores específicos subjacentes aos fatores amplos. Este modelo vem gradualmente sendo empregado como uma nomenclatura padrão entre pesquisadores e profissionais no entendimento da inteligência ${ }^{3}$.

Embora no modelo $\mathrm{CHC}$ a inteligência fluida $(G f)$ esteja situada em um nível hierárquico mais específico que o fator geral ela é, dentre os fatores amplos, o que mais se associa à concepção do fator $g$ de Spearman (1927). Carroll (1993) aconselha que o estudo das causas da complexidade de problemas de raciocínio indutivo, um dos fatores específicos de $G f$, poderá ajudar na interpretação do fator $g$, isto é, na compreensão dos processos cognitivos gerais presentes nas mais variadas habilidades cognitivas.

Segundo a concepção do fator $g$ toda atividade mental intelectual envolveria em maior ou menor grau uma única capacidade, indicando a existência de processos cognitivos comuns aos diferentes tipos de atividades mentais. Spearman (1927) buscou estudar a natureza do fator $g$ em termos de funcionamento cognitivo e o definiu a partir de três processos básicos: (a) apreensão das experiências significando uma capacidade ligada à percepção, à rapidez e à acuidade com que as pessoas percebem os estímulos, e bem como aos processos de auto-percepção da atividade consciente; (b) edução de relações referindo-se à capacidade maior ou menor de estabelecer relações entre duas ou mais idéias, sejam elas originadas da percepção ou de representações mnêmicas (por exemplo, pensar ou ver um elefante e uma garça e relacioná-los em uma categoria: animais; (c) edução de correlatos referindo-se à capacidade maior ou menor que as pessoas demonstram de criar novas idéias a partir de uma idéia e uma relação (por exemplo: a partir de uma categoria como a dos animais, evocar idéias particulares como jaca-

\footnotetext{
${ }^{3}$ Maiores informaçס̃es sobre a Teoria CHC podem ser encontradas no site http://www.iapsych.com especializado na divulgação e aplicação da Teoria CHC disponibilizando vários materiais, informações e uma lista de discussão sobre a teoria.
} 
rés, gorilas, quatis, etc). Estes processos estariam presentes em todas as atividades mentais não importando o conteúdo (matemático, verbal, artístico, etc).

A teoria $\mathrm{CHC}$ passou a identificar o fator $g$ como sendo mais próximo à inteligência fluida $(G f)$ referindo-se à habilidade de raciocinar em situações novas, diferentemente da inteligência cristalizada $(G c)$, referindo-se à habilidade de aplicar definições, métodos e procedimentos de solução de problemas, aprendidos previamente, para lidar com situações problema (Hunt, 1996). Quando as pessoas encontram uma situação-problema, elas precisam aglomerar um conjunto de procedimentos, que Snow, Kyllonen e Marshalek (1984) chamaram de "programas de performance", com o objetivo de resolver a questão existente. À medida que existirem programas de performance, isto é, esquemas de ação, armazenados na memória de longo prazo, a solução passa pela re- cuperação e aplicação desses esquemas $(G c)$. À medida que estes não existirem, eles precisarão ser criados. A pessoa deverá construir um novo programa de performance, organizando as informações disponíveis na situação e/ou reestruturando esquemas prévios. A inteligência $G f$ é, portanto, uma habilidade importante na previsão da capacidade geral de adaptação às situações novas, pouco estruturadas, que requerem autonomia intelectual. De acordo com Flanagan e Ortiz (2001): "a inteligência fluida refere-se às operações mentais que uma pessoa usa quando está defronte de tarefas novas que não podem ser executadas automaticamente. Estas operações mentais incluem o reconhecimento e formação de conceitos, a compreensão de implicações, resolução de problemas, extrapolação, e reorganização ou transformação de informações" (p.9).

Tabela 1: Fatores Específicos da Inteligência Fluida

\begin{tabular}{|c|c|c|}
\hline FATOR & DEFINIÇÃ̃O & EXEMPLO \\
\hline $\begin{array}{l}\text { Raciocinio } \\
\text { Sequiencial Geral } \\
(R G)\end{array}$ & $\begin{array}{l}\text { Habilidade associada ao raciocínio lógico- } \\
\text { sequiencial. isto é, iniciar com regras. premissas e } \\
\text { condiçōes declaradas e engajar em um ou mais } \\
\text { passos para chegar a solução para problemas } \\
\text { novos. E uma habilidade ligada a descoberta de } \\
\text { implicações subjacentes a certas idéias ou ligada } \\
\text { a combinação lógica entre elas. }\end{array}$ & $\begin{array}{l}\text { Uma loja vende produtos importados e nacionais entre vestidos } \\
\text { camisas e casacos. Alguns vestidos e todos os casacos fazem parte } \\
\text { dos produtos importados. Não há produto importado disponivel em } \\
\text { tamanho grande. Assirale qual dentre os fatos enunciados não } \\
\text { poderia ser verdadeiro: } \\
\text { A. Carla experimenta uma camisa nacional. } \\
\text { B. Luciama está comprando un casaco pequeno } \\
\text { C. Alberto pegou um casaco grande } \\
\text { D. Adriana experimenta um vestido pequeno. }\end{array}$ \\
\hline 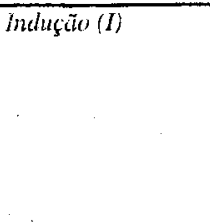 & $\begin{array}{l}\text { Habilidade para descobrir as características } \\
\text { fundamentais ou basais (e.g. regias, conceitos, } \\
\text { processos, tendências, pertinência a una classe) } \\
\text { que governam um problema ou um conjunto de } \\
\text { materiais. É uma habilidade ligada à descoberta } \\
\text { de regularidades observando-se vários exemplos } \\
\text { particulares representando aplicaçōes das regras. }\end{array}$ & $\begin{array}{l}\text { Qual figura ( } \mathrm{A}, \mathrm{B}, \mathrm{C} \text { ou } \mathrm{D}) \text { completa a analogia corretamente o } \\
\text { espaço com o ponto de interrogaçăo? }\end{array}$ \\
\hline $\begin{array}{l}\text { Raciocínio } \\
\text { Qucantitativo }(R Q)\end{array}$ & $\begin{array}{l}\text { Habilidade de raciocinar de maneira indutiva e } \\
\text { dedutiva sobre conceitos que envolvem relações e } \\
\text { propriedades matemáticas. }\end{array}$ & $\begin{array}{l}\text { Comprei um doce que custava R } \$ 1,00 \text {. Paguei com uma nota de } \\
\mathrm{R} \$ 5,00 \text { e dei a metade do troco para o meu irmão. Quanto dinheiro } \\
\text { dei para o meu irmão? }\end{array}$ \\
\hline $\begin{array}{l}\text { Raciocínio } \\
\text { Piagetiano (RP) }\end{array}$ & $\begin{array}{l}\text { Seriação, conservação; classificação e outras } \\
\text { habilidades cognitivas definidas por Piaget. }\end{array}$ & As tarefas clássicas usadas nos estudo de Piaget \\
\hline
\end{tabular}

No Estrato I, a inteligência fluida é composta por quatro fatores mais específicos apresentados na Tabela 1. Carroll (1993) analisou 236 tarefas de raciocínio ou fatores específicos em seu conjunto de 461 estudos e descobriu três grupos de tarefas gerais resultantes de inúmeras análises fatoriais destes estudos.

O primeiro fator chamado Raciocínio Sequiencial Geral $(R G)$ abarca tarefas que requisitam alguma forma de raciocínio dedutivo, isto é, a capacidade de derivar implicações ou conclusões a partir da análise de combinação de premissas 


\section{Ricardo Primi}

claramente formuladas seguindo dois ou mais passos lógicos. As tarefas de raciocínio dedutivo podem ser subdivididas em silogismos categóricos, silogismos lineares e raciocínio verbal geral. O segundo fator chamado Indução $(I)$ abarca atarefas de raciocínio indutivo nas quais a pessoa deve analisar um conjunto de estímulos observando as regularidades, as características comuns, para inferir as relações entre os estímulos. As tarefas de raciocínio indutivo podem ser subdivididas em: descoberta de conceitos/regras, seriação, tarefas de múltiplos exemplares, matrizes, elementos ímpares, analogias. O terceiro fator chamado Raciocínio Quantitativo $(R Q)$ indica as tarefas que utilizam o raciocínio dedutivo e indutivo mas mesclando-se com conceitos e relações quantitativas matemáticas principalmente de aritmética mas também álgebra, geometria e cálculo nos problemas mais difíceis.

Carroll (1993) descreve a dificuldade em separar os três fatores tendo encontrado somente um estudo no qual os três apareciam claramente diferenciados. Esta dificuldade derivou em parte em razão dos delineamentos que muitas vezes fatoravam variáveis que não representavam todo o espectro do raciocínio. Outra característica encontrada é que estes fatores são correlacionados e muitas vezes aparecem com um único fator interpretados como $g$. Outro ponto é a dificuldade em criar tarefas que meçam com pureza os processos únicos de cada fator. Por exemplo, mesmo em tarefas de indução no momento da resposta pessoa emprega a também a dedução seja pela aplicação da regra para a criação da resposta ou pela classificação de alguma resposta segundo a regra. As características elementares que diferenciam uma tarefa de indução de outra de dedução é a ênfase na descoberta da regras para a primeira e ênfase na combinação de regras e premissas claramente definidas na segunda.

Com relação às tarefas Piagetianas, Carroll (1993) analisou onze estudos que empregavam as medidas Piagetianas correlacionando-as com testes psicométricos. Ele concluiu que ainda não é claro como as dimensões subjacentes às tarefas Piagetianas se correlacionam com os três fatores amplos $R G, I \mathrm{e}$ $R Q$. Entretanto todas elas têm cargas fatoriais altas no fator geral. Esta, portanto, é uma área que precisa ser melhor investigada.

\section{Psicologia Cognitiva e Inteligência Fluida}

Uma das limitações do modelo psicométrico em razão do emprego da análise fatorial é a ênfase na faceta estrutural da inteligência (Sternberg, 1980). A capacidade cognitiva de uma pessoa utilizada na resolução de problemas da vida diária pode ser decomposta, segundo as teorias fatoriais, em diversos fatores como desenvolvimento lingüístico, informação, raciocínio indutivo, raciocínio seqüencial geral, visualização, memória, fluência verbal, etc. Entretanto, essas teorias não fornecem suporte para a compreensão de como essas capacidades entram em ação no momento em que a pessoa se defronta com os problemas da sua vida diária. Isto é, essas teorias não fornecem uma compreensão dinâmico-funcional da inteligência.

Partindo desta limitação na década de 60 um grande volume de estudos da psicologia cognitiva demonstrou, com maior clareza, a natureza dos processos cognitivos da inteligência fluida (BethellFox, Lohman \& Snow, 1984; Carpenter, Just \& Shell, 1990; Embretson, 1994, 1995, 1998; Evans, 1968; Goldman, \& Pellegrino, 1984; Gonzales Labra, 1990; Gonzales Labra \& Ballesteros Jimenez, 1993; Green \& Kluever, 1992; Hornke \& Habon, 1986; Mulholland, Pellegrino \& Glaser, 1980; Pellegrino, \& Glaser, 1979; Rumelhart \& Abrahamson, 1973; Sternberg, 1977; Sternberg \& Gardner, 1983). No Brasil estudos deste tipo foram realizados por Primi (1995, 1998, 2002), Primi e Rosado (1995), Primi, Rosado e Almeida (1995). Tais estudos investigam os processos cognitivos envolvidos em tarefas apresentadas em testes psicométricos. $\mathrm{O}$ estudo considerado clássico nesta área é o de Sternberg (1977) que propôs um novo método chamado análise componencial a partir do qual é possível analisar os passos cognitivos que as pessoas executam quando resolvem problemas em testes psicométricos. Este método será discutido a seguir.

\section{Estudos iniciais dos componentes cognitivos do raciocínio analógico}

Dentro do domínio da inteligência fluida, os problemas de raciocínio analógico são uma tarefa freqüentemente utilizada para avaliar raciocínio 
indutivo. Esta forma de raciocinar se relaciona ao processo de aplicar, analogamente, um conjunto de informações ou relações de um domínio bem conhecido a outro desconhecido, criando, com isto, novas informaçōes em campos desconhecidos. Geralmente os itens de raciocínio analógico seguem o formato A está para $B$ assim como C está para $D$ (A:B / C:D) como o exemplo do Fator $I$ apresentado na Tabela 1. Formatos como este exigem do sujeito a capacidade de inferir relações entre os dois primeiros termos (evento conhecido) e aplicá-las ao terceiro termo, encontrando a parte que falta (evento desconhecido).

Sternberg (1977) estudou experimentalmente o processo de solução de analogias de conteúdo verbal, geométrico e figuras esquemáticas de pessoas. Uma das manipulações experimentais feitas neste estudo criava quatro maneiras de apresentação das analogias. Considerando o formato $A: B / / C: D$, na primeira condição o primeiro termo (A) era apresentado em uma tela de um taquistoscópio e os participantes observavam este estímulo o tempo que quisessem. Estando prontos para continuar, os participantes pressionavam uma tecla fazendo com que a analogia toda $(\mathrm{A}: \mathrm{B} / / \mathrm{C}: \mathrm{D})$ aparecesse ná tela. Nas três condições restantes, ocorria a mesma seqüência, variando somente o número de elementos que apareciam na apresentação preliminar $(\mathrm{A}: \mathrm{B}, \mathrm{A}: \mathrm{B} /$ $C$, e uma tela branca). $O$ experimentador media o tempo de reação transcorrido na segunda parte da apresentação. Além desta manipulação interferindo no número de elementos que deveriam ser processados na segunda parte, Sternberg variou sistematicamente cada item de forma a aumentar ou diminuir a complexidade das relações entre os termos $A: B$ que deveriam ser descobertas durante a resolução.

Sternberg (1977) postulou, inicialmente, um modelo de processamento envolvendo cinco componentes principais e uma alternativa: codificação, inferência, mapeamento, aplicação, resposta e justificativa. Estes estariam encadeados em uma estratégia como se descreve a seguir. Em uma analogia do tipo $\mathrm{A}: \mathrm{B} / / \mathrm{C}:$ ? D1 ou D2, por exemplo: Automóvel : Estrada / Trem : (A) Estação, (B) Trilho. Inicialmente o sujeito codifica os dois termos (A e B) de maneira serial e exaustiva, recuperando da memória a longo prazo, os atributos relacionados aos conceitos, bem como valores particulares dentro do espectro de variação destes atributos; em seguida, o sujeito infere as relações entre todos os atributos codificados para os dois termos, armazenando as relações encontradas na memória de trabalho. Após a inferência, o sujeito codifica o terceiro termo da analogia, recuperando seus atributos e em seguida mapeia as relações existentes entre ele e o primeiro termo e armazena na memória as relações encontradas. Em seguida, o sujeito codifica as alternativas (termos D1e D2), e aplica, para o termo $\mathrm{C}$, as relações encontradas para os termos $\mathrm{A}: \mathrm{B}$. Se o sujeito consegue distinguir uma única solução entre as respostas possíveis (ou seja, um termo $\mathrm{D}$ que forme uma relação $\mathrm{C}: \mathrm{D}$ análoga a $\mathrm{A}: \mathrm{B})$, então o sujeito responde. Se isto não for possível, ou seja, se nenhum dos atributos recuperados e aplicados consegue fazer esta distinção, então o sujeito inicia um novo componente de justificativa por meio do qual descobre a melhor resposta possível, justificando as razões encontradas.

Supondo que este modelo fosse verdadeiro e supondo ainda que o processamento ocorra em série, o tempo de resolução das analogias é igual à soma do número de vezes em que cada componente é executado. Sendo assim, o tempo de reação pode ser previsto por equações lineares, como é exemplificado na Tabela 2.

Tabela 2: Demonstração de duas formas possíveis de divisão de uma tarefa de raciocínio analógico

\begin{tabular}{c|c|c|c}
\hline CONDIÇão & \multicolumn{1}{|c|}{ FASE } & \multicolumn{1}{|c|}{ FASE DE RESOLUÇÃo } & PREVISÃo DO TEMPO DE REAÇÃo \\
\hline 1 & Nada & Alitomóvel : Estrada / Trem : ? (A) Estaçĩo, (B) Trilho & TR $=5 \operatorname{cod}+X$ inf $+Y$ map $+Z$ ap/ + res \\
\hline 2 & Automóvel : Estrada & Automóvel : Estrada / Trem : ? (A) Estaçño, (B) Trilho & $T R=3$. cod $+Y$ map $+Z$ ap/ + res \\
\hline
\end{tabular}

Nela são descritas as equações para duas condições de apresentação. Na primeira condição, todos os termos devem ser codificados na fase de resolução pois nenhum termo foi apresentado na fase preliminar. Logo, 5 termos devem ser codificados ( 5 cod). Na segunda condição os termos $A: B$ são apresentados na fase preliminar. Logo, estes dois termos são codificados $(2 \operatorname{cod})$ e as relações entre eles são 


\section{Ricardo Primi}

inferidas ( $X$ inf) neste momento inicial. Na fase de resolução, portanto, somente três termos devem ser codificados $(3 \operatorname{cod})$ e o restante dos componentes devem ser processados $(Y$ map $+Z a p l+r e s)$. Portanto, a cada condição os componentes são sistematicamente eliminados na fase de resolução e as equações de previsão do tempo de reação irão refletir esta eliminação.

Basicamente, nas equações estão envolvidos parâmetros (cod, inf, map, apl, res) representando o tempo requerido por cada componente e variáveis independentes relacionadas às manipulações experimentais que controlam o número de vezes que os componentes devem ser processados. Utilizando a regressão múltipla é possível estimar os valores dos parâmetros (cod, inf', map, apl, res) das equações indicando o tempo requerido no processamento de cada passo no processo de resolução. Sendo o modelo verdadeiro, esta equação teria sucesso em prever o tempo de reação, fazendo com que a correlação entre o tempo previsto e o encontrado fosse alta. De modo geral os resultados de foram bem sucedidos em prever o tempo de reação e estimar, portanto, o tempo requerido em cada componente (Sternberg, 1977).

A análise componencial inspirou vários estudos sobre o processamento cognitivo envolvidos na resolução de testes psicométricos de raciocínio. Dentre eles; Mulholland e cols. (1980) pesquisaram mais detalhadamente as analogias com figuras geométricas. Segundo eles "uma fragilidade da teoria de Sternberg em seu estado corrente se relaciona à idéia de que o processo de codificação é exaustivo e de que a representação dos atributos associados a um dado termo da analogia são independentes do contexto. É difícil conceber como a codificação de uma nova palavra ou figura, em um problema de analogia, sem que um termo anterior ou posterior - ou seja o contexto - gere uma tendência que determine o nível mais apropriado da representação do item na memória" (p.254).

Com base nestes pontos Muholland e cols (1980) delinearam uma pesquisa destinada a verificar mais detalhadamente o processo de codificação manipulando sistematicamente o número de elementos que compunham cada termo individual, e simultaneamente o número de transformações ocorridas entre estes termos. Assim, foram operacionalizadas as variáveis que interferem no componente de codificação (ou seja, o número de atributos que eram os elementos que compunham cada termo individual) e no componente de inferência das relações (transformações nos elementos). Em seu delineamento, os itens do teste representavam composições fatoriais dessas duas variáveis. Portanto, não havia, como na pesquisa de Sternberg (1977), condições de pré-apresentação.

Nesta pesquisa, foram pressupostos quatro componentes de processamento envolvidos na resposta ás analogias: (a) comparação e decomposição de padrões, (b) análise de transformações e geração de regras, (c) comparação de regras e (d) resposta. Neste estudo as analogias eram semelhantes ao exemplo apresentado para o fator Indução na Tabela 1, entretanto, no formato verdadeiro ou falso, isto é, apresentava-se uma analogia completa incluindo o termo $D$ e a atarefa do sujeito consistia em dizer se a analogia era correta ou não. De acordo com o modelo de Muholland e cols (1980) nestes itens inicialmente o sujeito compara os dois primeiros termos, identificando os elementos comuns que os compõem. Cada padrão identificado é analisado quanto às transformações ocorridas. Identificada a transformação, esta é armazenada na memória de trabalho em forma de proposições que dizem respeito aos elementos e suas transformações. Este processo de identificação de um padrão e análise das transformações se repete até que se eliminem todos os padrões encontrados para os termos "A e B". O mesmo processo ocorre para os termos "C e D", só com uma diferença. Já que a forma dos itens pesquisados era do tipo verdadeiro-falso, depois que a transformação para o primeiro termo é encontrada, ela é comparada com as proposições armazenadas na memória. Se essas não forem semelhantes, o sujeito responde que a analogia é incorreta. Contudo, se elas forem semelhantes, ele continua o processo de identificação e análise do próximo elemento. Ao final verifica-se se todos os elementos foram comparados. Se, neste processio, não houve nenhuma dessemelhança, o sujeito responde que a analogia é correta. Caso contrário, responde que esta é incorreta.

As principais diferenças entre este modelo e 0 de Sternberg (1977), estão no processo de codificação 
e na estratégia geral que relaciona os componentes. Nota-se, portanto, que este modelo pressupõe que a codificação de um termo se faz em relação ao segundo termo. O sujeito, em um processo de análise, compara os dois termos, selecionando os atributos relevantes da analogia, ou seja, os padrões de que são compostos os termos. Na medida em que os padrões são encontrados, eles são analisados quanto às transformações ocorridas, gerando, com isto, uma lista de proposições que representam os padrões e suas transformações. Além disso, este modelo postula a estratégia: inferência-inferência-comparação, enquanto o modelo de Sternberg postula a estratégia: inferência-mapeamento-aplicação.

Segundo Mulholand e cols (1980) a equação de regressão simplificada que prevê o tempo de reação em seus itens seria: $T R=x E+y T+k$ na qual $E$ é igual ao parâmetro estimado para o processo de comparação e decodificação dos padrões individuais; $x$ é a variável independente referente ao número de elementos existentes na analogia; $T$ é o parâmetro estimado para o processo de análise de transformações e geração de regras individuais; $y$ é a variável independente referente ao número de transformações e comparações exigidas em cada analogia particular e $k$ é uma constante ligada à resposta.

Contudo, os resultados obtidos violaram a simples aditividade, gerando efeitos superaditivos em função da interação das variáveis $T$ e $E$. Uma razão potencial para isto é que em níveis mais altos de dificuldade (número alto de $T$ e $E$ ) um tempo maior é gasto em processos ligados à memória, já que um grande número de proposições referentes aos elementos e suas transformações devem ser armazenadas. Portanto, Mulholand e cols (1980) consideram que os processos envolvidos nos dois componentes são aditivos, e as sobrecargas de memória seriam a explicação para o aumento do tempo de reação em itens difíceis. Logo a equação de regressão final asșumiu a seguinte forma: $T R=x E+y T+T E+k$, onde $T E$ é igual ao tempo gasto no componente ligado à memória.

\section{Os componentes de processamento cognitivos para problemas em matrizes}

De um modo geral, o trabalho de Mulholland e cols (1980) trouxe avanços significativos possibilitando uma maior compreensão dos processos envolvidos no processamento de analogias geométricas. No entanto grande parte das tarefas mais importantes de raciocínio analógico usadas na avaliação da inteligência fluida consiste em figuras geométricas dispostas em matrizes como o item exemplificado na Figura 1 usado em Primi (1998, 2002).

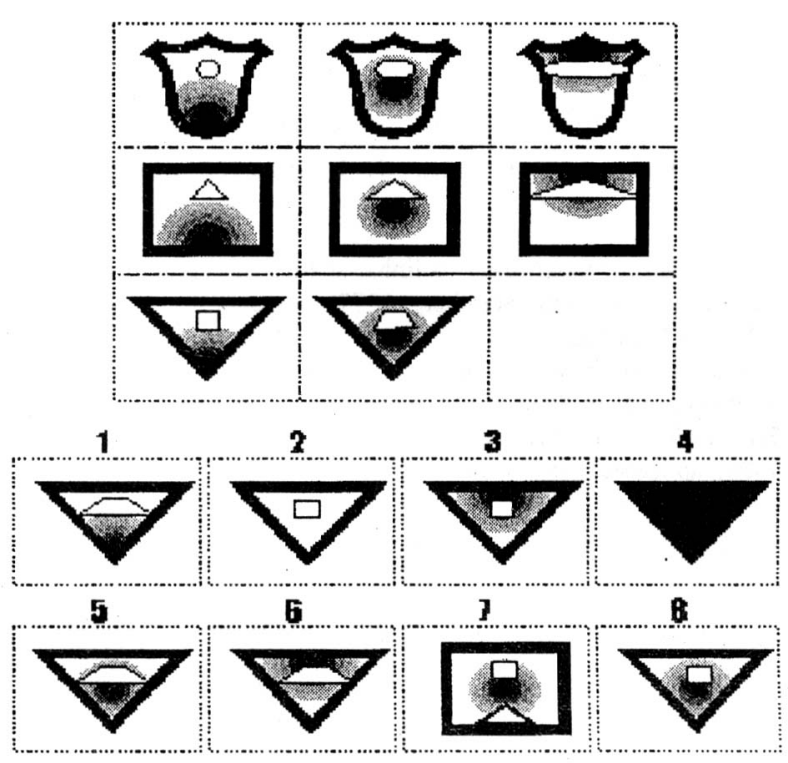

Figura 1: Exemplo de item de raciocínio analógico com figuras geométricas dispostas em matrizes.

Em problemas desse tipo, as figuras geométricas estão dispostas segundo regras subjacentes que necessitam ser descobertas, possibilitando a extrapolação no reconhecimento de qual, dentre às oito alternativas, completa corretamente o espaço deixado em branco no canto inferior direito da matriz de nove quadros.

O modelo de processamento para itens desse tipo, adotado nesse estudo, será descrito com o auxílio da Figura 2. Nela apresentam-se os principais sistemas envolvidos no processo de resolução (memória de longo prazo, memória de trabalho, sistema sensorial perceptual e sistema motor) representados pela cor cinza indicando seu estado de ativação.

O processamento foi dividido em três blocos, denominados dessa maneira por incluírem mais de um componente de processamento. Esses blocos são: (a) um bloco associado à criação das representações 


\section{Ricardo Primi}

mentais que compõem o problema e à criação de regras que descrevem seu relacionamento; (b) um bloco ligado ao reconhecimento dos paralelos entre a regra e uma situação nova e sua confirmação; (c) a aplicação dessas regras na criação de alternativas para o problema. Esse modelo foi resultado de uma tentativa de integração das descobertas da literatura, principalmente no trabalho de Carpenter \& cols. (1990) que estudou os processos de resolução das Matrizes Progressivas de Raven (Raven, 1962; Raven, Raven \& Court, 1998). Esse estudo é o que propõe o modelo mais adequado para itens do tipo apresentado na Fi- gura 2, já que, como apontaram Pellegrino e Lyon (1979), o estudo clássico de Sternberg (1977), e muitos que o seguiram, utilizaram analogias relativamente fáceis, não ambíguas e, portanto, os modelos propostos nesses estudos não seriam automaticamente generalizáveis para analogias mais complexas como as que foram utilizadas aqui. De fato, Carpenter e cols. concluíram que "a análise do raciocínio em analogias simples ilumina os processos de inferências específicos da tarefa, mas são improváveis em representar as diferenças individuais em tarefas de raciocínio mais complexas"(p. 429).

Primeiro Bloco: input primeira linha, análise perceptual e análise conceitual (indução de regras) (Carpenter, Just \& Shell, 1990); codificação e inferência de relaçőes (Stemberg, 1977), comparação e decomposição de elemento, análise de transformações e geração de regras (Mulholland, Pellegino \& Glaser, 1980).

Segundo Bloco: input segunda linha, análise perceptual, análise conceitual (generalização)

(Carpenter, Just \& Shell, 1990), mapeamento (Sternberg, 1977), comparação de regras (Mulholland, Pellegino \& Glaser, 1980).

Terceiro Bloco: input terceira linha, análise perceptual, análise conceitual (generalização), geração e seleção de uma resposta (Carpenter, Just \& Shell, 1990), aplicaçăo, comparação e resposta (Sternberg, 1977), comparação de regras, resposta (Mulholland, Pellegino \& Glaser, 1980).

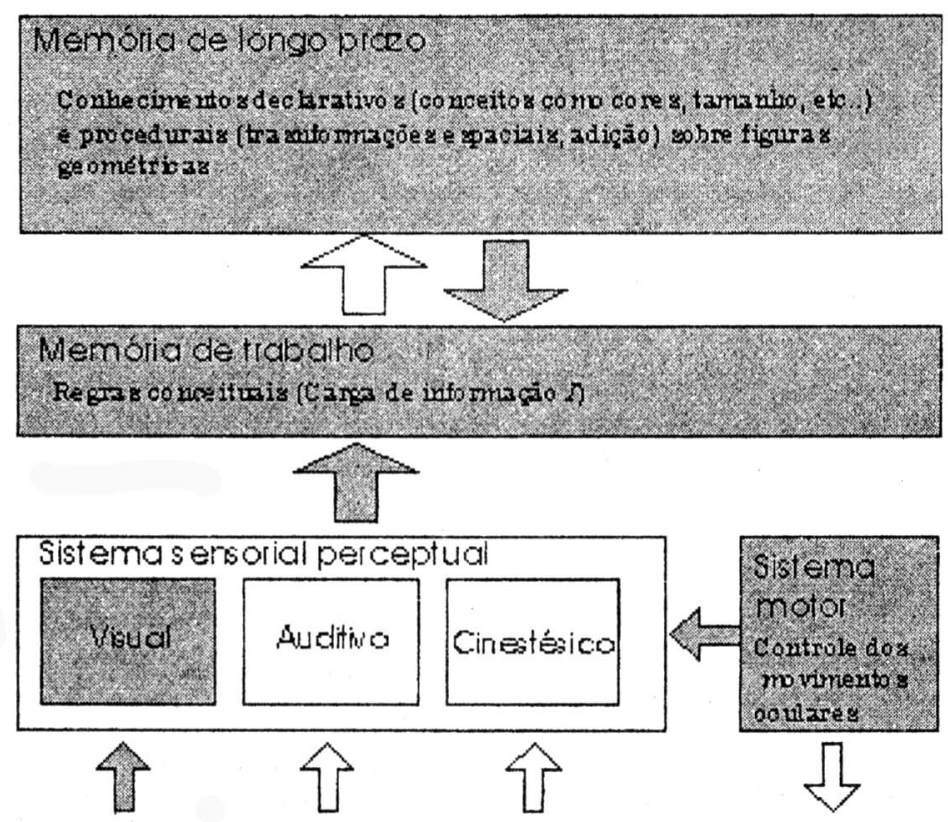

Figura 2: Representação esquemática das estruturas ativas (preenchidas em cinza) no processamento de problemas de raciocínio indutivo

Primeiro bloco: iniciando a resolução das analogias, os sujeitos observam a primeira linha e percebem várias figuras não relacionadas. Em cada parte da matriz na qual fixem a atenção, verão um elemento independente. Iniciam então um processo básico de comparação perceptual, buscando similaridades e diferenças entre os estímulos e abstraindo do padrão complexo um elemento ou atributo por vez.

Nesse momento estão ativos o controle motor dos movimentos oculares e o sistema de percepção visual. $O$ controle motor organiza o fluxo dos estímulos que entram pelo sistema de percepção visual. Provavelmente, nessa fase, os atributos 
perceptuais dos estímulos e os processos internos de organização perceptual tenham grande influência no agrupamento de elementos ou atributos, de forma que estímulos semelhantes, mais próximos ou com uma continuidade natural, mostrarão uma maior tendência a serem agrupados (Primi, 1995).

Depois desse agrupamento perceptual, o sujeito cria uma regra verbal conceitual, descrevendo as transformações perceptuais que observa entre os elementos ou atributos das figuras ao longo das três colunas da primeira linha. Essa regra é então armazenada na memória de trabalho. Em seguida passa ao próximo atributo ou elemento, executando o mesmo bloco de análise perceptual e indução e incrementando a regra.

No primeiro bloco é ativada a memória de longo prazo para a recuperação de informações declarativas e procedurais específicas sobre esse domínio, como conceitos sobre atributos de estímulos visuais e seus respectivos códigos verbais, conhecimentos sobre como transformar estímulos visuais, etc. À medida que a regra é gerada, ativa-se a memória de trabalho para o efetuar seu armazenamento. A carga de informação I aumentará proporcionalmente ao número de variáveis envolvidas no problema, isto é, ao número de atributos ou elementos.

Segundo bloco: tendo processado todas as variáveis envolvidas, o sujeito passa a analisar a segunda linha, comparando perceptualmente seus elementos ou atributos. Nesse momento, se a regra inferida for correta, ocorre simultaneamente o reconhecimento de que as transformações observadas são instâncias da regra geral inferida anteriormente. Em cada parte da segunda linha que os sujeitos fixem a atenção verão, em vez de uma nova figura como antes viam, uma instância particular de uma regra conceitual, ou seja, solidificarão a representação conceitual do problema, tornando-a mais estável.

Neste momento estão ativos o sistema motor, a memória de trabalho e o sistema de percepção visual. A carga de informação I provavelmente permanece inalterada, já que a mesma regra inferida anteriormente representa adequadamente a situação nova:

No entanto, esse pode não ser sempre o caso, pois se a regra inferida na primeira linha não for a correta, isto é, se ela agrupa atributos que não são relevantes para a solução do problema, ele perceberá a inconsistência nesse momento, e precisará operar sobre as informações armazenadas na memória de trabalho sobrecarregando-a. O sujeito terá que comparar as regras $x$, inferida na primeira linha, e $y$, inferida na segunda, e decidir se irá descartar uma delas ou manter as duas. Ele pode decidir descartar a regra $y$, por exemplo, se observar que essa regra tem um poder de generalidade menor. Por outro lado, pode decidir pela manutenção da regra quando, por exemplo, descobre que ela se relaciona a um segundo atributo envolvido no problema. Nessa situação, a carga I na memória de trabalho aumenta momentaneamente e, se o resultado da operação for a manutenção das novas regras geradas, então esse aumento permanece.

Terceiro bloco: em seguida o sujeito passa para a terceira linha, novamente analisando-a perceptualmente, mapeando os elementos ou atributos, reconhecendo-os como instâncias da regra geral e, por fim, aplicando-a para construir uma alternativa para o problema. Essa fase, portanto, requer a operação sobre as informações na memória de trabalho. O sujeito deve gerar uma representação mental derivada da regra que mantém armazenada na memória de trabalho. Depois, compara a alternativa criada com as alternativas propostas, escolhe aquela mais semelhante e responde.

Nesse bloco os mesmos sistemas que já estavam ativos continuam ativos. A carga de informação I na memória de trabalho aumenta, uma vez que o sujeito deve armazenar a reposta criada para compará-la com as alternativas.

\section{Inteligência Fluida e Memória de Trabalho: os estudos da Neurociência Cognitiva e Neuropsicologia}

Até aqui vimos discutindo detalhadamente os modelos desenvolvidos pela psicologia cognitiva para a resolução de problemas em tarefas encontradas nos testes de inteligência fluida. Em relação a psicometria estes modelos representam um avanço para o estudo da inteligência já que descrevem os processos mentais envolvidos na resolução destes problemas. Recentemente estes modelos vêm 


\section{Ricardo Primi}

evoluindo e se aproximando cada vez mais das pesquisas desenvolvidas pela neurociência, especialmente aquelas ligadas às imagens cerebrais (PET, fMRI), e pela neuropsicologia. A integração destes estudos define um novo campo chamado neurociência cognitiva que busca decompor os processos cognitivos e emocionais realizados pelo cérebro (Posner \& Digirolamo, 2000). Para concluir a revisão sobre o conceito da inteligência fluida serão apresentados os principais estudos mais recentes nesta abordagem que vem possibilitando uma maior compreensão deste tipo de inteligência procurando integrá-los aos estudos discutidos acima. O elo de ligação entre os estudos da neurociência cognitiva $e$ a inteligência fluida reside no estudo da memória de trabalho.

\section{A memória de trabalho}

A memória é tradicionalmente dividida em dois grandes sistemas a memória de curto prazo e a memória de longo prazo. A primeira tem uma capacidade limitada e serve ao armazenamento de informações por um curto período de tempo e a segunda, praticamente ilimitada, serve ao armazenamento de informações aprendidas a partir da interação com o meio e as mantém disponíveis por um longo período de tempo. No modelo psicométrico as habilidades ligadas à memória são representadas em três capacidades amplas: memória de curto prazo $(\mathrm{Gsm})$, fluência de armazenamento e

recuperação da memória a longo prazo $(G l r)$ e a inteligência cristalizada $(G c)$ referindo-se ao estoque de informações armazenadas na memória de longo prazo.

A concepção tradicional do modelo psicométrico para memória de curto prazo a descrevia como capacidade simples para o armazenamento de informações em um breve espaço de tempo como, por exemplo, lembrar o nome de uma pessoa segundos depois de ter sido apresentado a ela. De acordo com esta concepção a avaliação da memória pode ser feita pedindo que a pessoa repita listas de palavras simples que vão progressivamente aumentando em tamanho testando-se até quantas palavras a pessoa consegue repetir corretamente (este tipo de medida se chama extensão de memória [memory span]).

Entretanto, a partir da década de setenta Alan Baddeley \& Graham J. Hich propuseram um modelo mais complexo composto por três sub componentes que, por diferir do sistema unitário de memória de curto prazo, passou denominar este construto de memória de trabalho (Baddeley, 1996b, 1998; Baddeley \& Hitch, 1994).

De acordo com este modelo a memória é composta por três subsistemas. Os dois primeiros são responsáveis pelo armazenamento temporário de informações e são chamados de sistemas escravos por servirem ao terceiro componente associado ao processamento das informações. Estes sistemas são representados na Figura 3.

Memória de Trabalho

Figura 3: Modelo para a memória de trabalho de acordo Alan Baddeley e Graham J. Hich
Unidade de process amento

Roecutivo Central

Controle da atengão (atengĩo seletiva)

Cocirdenagão de atividades mentais

Selegāo, ativa ȳ̃o e manipulagäo de infomma çōes

da memónia da longo praco

Buffers de Ammozenamento

Cido Foumbogica
Finfomaḡes
auditivas, verbais

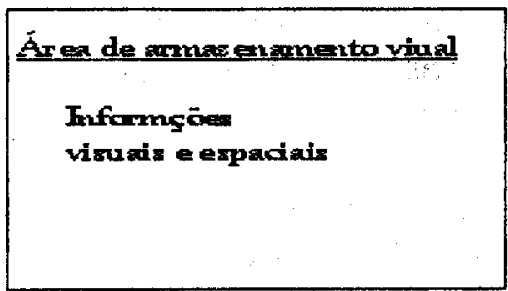


O primeiro chamado ciclo fonológico (phonological loop) é responsável pelo armazenamento de informações acústicas (ou ligadas à fala) e consegue manter traços por dois ou três segundos. Depois deste intervalo os traços de memória só permanecerão ativos por mais tempo se ocorrer alguma estratégia de repetição.

O segundo, chamado área de armazenamento visual-espacial (visuo-spatial sketch pad), é responsável pelo armazenamento de informações visuais. Este subsistema é dividido ainda em uma parte especializada no armazenamento de informações espaciais, por exemplo, sobre a lacalização de objetos, e outra especializada em informações sobre as propriedades de estímulos visuais, por exemplo, a aparência de objetos.

Os sistemas ciclo fonológico e área de armazenamento visual têm capacidades limitadas de armazenamento e este limite varia de pessoa a pessoa, isto é, existe uma grande variabilidade individual quanto à capacidade de armazenamento.

O terceiro, chamado de executivo central (central executive) é responsável pelo processamento cognitivo ligado ao ciclo fonológico e à área de armazenamento visual. Baddeley (1996b) define a memória de trabalho como "um sistema de capacidade limitada capaz de armazenar e manipular informações" (p. 13488). Portanto ao invés de referirse simplesmente à capacidade de armazenamento, a memória de trabalho refere-se à capacidade de armazenamento + processamento fazendo-a distinta do construto memória e curto prazo anteriormente concebido. Portanto, o executivo central é elemento que faz a memória de trabalho diferir do conceito de memória de curto prazo integrando uma estrutura mais funcional ligada ao processamento além das estruturas ligadas ao armazenamento como antes se concebia.

Esta distinção é claramente percebida nas tarefas criadas para avaliar a memória de trabalho. Por exemplo, Kyllonen e Christal (1990) criaram medidas de memória envolvendo simultaneamente a manutenção e manipulação de informações. Eles pedem aos sujeitos que memorizem algumas equações como: $\mathrm{A}=\mathrm{C}+3 ; \mathrm{C}=\mathrm{B} / 3 ; \mathrm{B}=9$, e depois perguntam o valor de $\mathrm{A}, \mathrm{B}$ e C. Outra tarefa clássica de medida da memória de trabalho é chamada extensão em leitura (reading span) criada por Daneman e Carpenter (1980). Nesta tarefa os sujeitos devem ler listas com duas a seis frases tais como (exemplo com duas frases): "O táxi entrou na avenida Michigan onde eles tiveram uma bela vista do lago / Quando finalmente seus olhos abriram, não havia o brilho do triunfo e nem uma sombra da raiva" e após a leitura devem responder algumas perguntas e ao final repetir a última palavra de cada frase. Como pode ser observado além do armazenamento estas tarefas requerem simultaneamente o processamento das informações apresentadas.

\section{O executivo central e a inteligência fluida}

A relação entre a inteligência fluida e a memória de trabalho passou a ser evidente quando as pesquisas mostraram que medidas de memória de trabalho se correlacionavam com atividades cognitivas complexas ligadas aos fatores psicométricos (Jurden, 1995). Três trabalhos são mais relevantes e conhecidos: Carpenter e cols. (1990), Daneman e Carpenter (1980) e Kyllonen e Christal (1990).

Daneman e Carpenter (1980) compararam as correlações de medidas tradicionais de memória de curto prazo, que só requerem a habilidade de armazenar informações, e medidas de memória de trabalho, requerendo o armazenamento e processamento, com a habilidade verbal medida pelo SAT (Scholastic Assessment Test $)^{4}$ um teste usado na seleção de alunos para as universidades americanas. Os autores encontraram uma correlação de $0,59(p<0,01)$ para memória de trabalho e 0,35 (n.s.) para memória de curto prazo concluindo que a memória de trabalho é elemento crucial na compreensão da linguagem.

Kyllonen e Christal (1990) fizeram um extenso estudo empregando a análise fatorial confirmatória investigando a estrutura fatorial subjacente a um conjunto de provas de inteligência cristalizada, inteligência fluída e memória de trabalho. Eles encontraram correlações entre 0,82 a 0,88 entre medidas raciocínio e memória de trabalho concluindo com uma frase que ficou famosa no âmbito acadêmico que titulava o artigo relatando esta pesquisa: " $\mathrm{A}$ habilidade de raciocínio é (um pouco mais que) a ca-

${ }^{4}$ Mais informações sobre este teste podem ser obtidas em http; lwww.collegeboard.com/ 


\section{Ricardo Primi}

pacidade de memória de trabalho?"

Carpenter e cols. (1990) fizeram uma análise extensa e bastante interessante do processamento cognitivo envolvido na resolução das Matrizes Progressivas de Raven um teste clássico de raciocínio indutivo ou inteligência fluida (Raven, J., Raven J. C. \& Court, 1998). Uma das descobertas é que a complexidade dos itens aumenta a medida em que há mais regras a serem consideradas nos problemas. Por isso para resolver estes problemas a pessoa precisa possuir "habilidade de gerar submetas na memória de trabalho, armazenar a satisfação destas submetas, e planejar novas submetas a medida que outras são atingidas" (p. 413). Este processo de geração e manutenção de metas na memória claramente requer além do armazenamento o processamento das informações o que supõe que a resolução deste teste depende muito da memória de trabalho. Em um dos experimentos os participantes responderam ao Raven e a Torre de Hanói um jogo com grande dependência da memória de trabalho. A correlação entre a quantidade de erros cometidos nos dois instrumentos foi muito alta $(r=0,77 ; p<0,01)$ sugerindo, como o estudo de Kyllonen e Christal (1990), que a capacidade de memória é uma das mais importantes capacidades envolvidas na resolução do Raven.

A partir de estudos como estes vários outros foram feitos procurando relacionar medidas de raciocínio ligadas ao fator inteligência fluida e memória de trabalho tais como os de Embretson $(1995,1998)$. Mesmo Carroll (1993) já antecipava esta linha de pesquisa em seu estudo fatorial clássico (p. 247).

Mais recentemente Engle, Tuholski, Laughlin e Conway (1999) realizaram um estudo das correlações entre medidas de memória de curto prazo, envolvendo o armazenamento simples, medidas de memória de trabalho, envolvendo o armazenamento simultaneamente ao processamento cognitivo, medidas de inteligência fluida (Raven e Testes Livres de Viés Cultural de Cattell) e o SAT. Os autores usaram a análise de estruturas de covariância permitindo a testagem de vários modelos buscando explicar as correlações encontradas. A hipótese central era que o processo básico ligado ao executivo central é atenção controlada. $O$ controle do foco da atenção permite que a pessoa consiga manter representações mentais ativas mesmo em condições de distração quando outros estímulos competem pela atenção. Este processo relaciona-se à ativação de certas representações mentais e também pela inibição de outras representações distratoras.

A lógica do estudo de Engle e cols. (1999) sustenta-se na idéia de que ambas medidas de memória de curto prazo e medidas de memória de trabalho requerem o armazenamento de informação mas somente as medidas de memória de trabalho requerem o controle da atençã̃o, já que envolvem a execução de múltiplas tarefas simultaneamente. Sendo assim argumentam que as correlações entre medidas de memória de curto prazo e memória de trabalho ocorrem por causa da capacidade de armazenamento. A variância residual da medida de memória de trabalho, após o controle estatístico removendo a variância comum com a memória de curto prazo, corresponderia às diferenças individuais na capacidade de controle da atenção sendo este o construto que estaria envolvido nos testes de inteligência fluida. Os resultados de Engle e cols. corroboraram esta idéia mostrando uma correlação de 0,49 $(p<0,05)$ entre o resíduo de medidas de memória de trabalho com o fator inteligência fluida depois que o componente ligado ao armazenamento foi estatisticamente removido ao passo que a correlação entre memória de curto prazo e a inteligência fluida depois do controle estatístico foi de 0,12 (n.s.).

Em outro estudo Kane, Bleckley, Conway e Engle (2001) avaliaram mais diretamente as correlações entre as diferenças individuais em memória de trabalho e o controle de atenção. Os autores compararam sujeitos com alta e baixa capacidade de memória de trabalho em duas tarefas. Uma delas que exigia exclusivamente o controle da atenção para evitar uma resposta automática. A tarefa controle exigia uma resposta quase automática não exigindo controle da atenção e nem memorização. Os resultados indicaram diferenças de desempenho entre os sujeitos com alta e baixa capacidade de memória de trabalho na primeira tarefa indicando que a memória de trabalho esta associada ao controle da atenção.

Em outro estudo recente Miyake, Friedman, Rettinger, Shah e Hegarty (2001) empregaram procedimentos de análise semelhantes aos de Engle e cols. (1999) mas no domínio das habilidades visuais. Este estudo analisou as correlações entre medi- 
das de memória de trabalho visuo-espacial, memória de curto prazo visuo-espacial, medidas da função executiva e três fatores específicos de processamento visual $(G v)$ : visualização, relações espaciais e velocidade perceptual. No estudo de Engle e cols (1999) as medidas de memória eram predominantemente verbais ligadas ao ciclo fonológico. Já no estudo de Miyake e cols. (2001) elas eram ligadas à área de armazenamento visual. Os autores encontraram uma alta correlação entre medidas de memória de curto prazo e memória de trabalho visuais indicando que as duas dependem na mesma medida do executivo central. Enquanto no estudo de Engle e cols. ficou evidente que o ciclo fonológico, ou a memória de curto prazo verbal, embora altamente correlacionada, é distinta do executivo central, o estudo de Miyake e cols. indicou que a memória visual é praticamente indistinguível do executivo central. Uma das explicações para isso é que as pessoas estão muito mais habituadas em lidar com representações auditivoverbais do que usar representações visuais. Conseqüentemente as tarefas verbais seriam mais automáticas e menos dependentes do executivo central quando fossem realizadas com poucas informações. Ao contrário as tarefas visuais, mesmo envolvendo de uma pequena quantidade de informação, já sobrecarregaria o sistema de memória exigindo o executivo central.

Os estudos citados acima permitem concluir que a relação entre memória de trabalho e inteligência fluida ocorre em razão de ambas dependerem das funções realizadas pelo executivo central. Ambas as tarefas requerem o armazenamento de várias informações e a execução simultânea de processos cognitivos de transformação dessas informações ultrapassando o montante de informações que os buffers de armazenamento (ciclo fonológico e área de armazenamento visual) conseguem manter ativas. Portanto é necessário um controle ativo e voluntário dos processos de atenção para organizar a atividade mental para que resolução possa ser atingida. Como afirma Hunt (1999) as tarefas exigem "estruturas de controle da atenção que possibilitam às pessoas fixarem atenção em um ou outro item na memória ... assegurando um fluxo ordenado de informações para a memória de trabalho, vindas do mundo externo e/ ou da memória por si mesma, seja bloqueando infor- mações não pertinentes, ou eliminando informações que parecem não ser úteis para a resolução do problema" (p. 8).

Portanto, a definição dos processos cognitivos e das habilidades básicas ligadas a estes processos para inteligência fluida reside no estudo do executivo central. Baddeley (1996a) faz uma revisão de suas pesquisas tentando elucidar os processos básicos subjacentes ao executivo central e os divide em quatro capacidades: (a) capacidade de coordenar atividades mentais simultâneas dos dois sistemas de armazenamento (ciclo fonológico e área de armazenamento visual), (b) capacidade de supervisionar a atividade mental alternando estratégias automáticas com estratégias novas quando necessário, (c) capacidade de atenção seletiva, isto $e$, prestar atenção em informações específicas relevantes e ao mesmo tempo inibir a ativação de outras informações irrelevantes e (d) capacidade de ativação de informações da memória de longo prazo.

Este último componente é importante pois relaciona a memória de trabalho com a memória de longo prazo. Engle e cols. (1999) cita um modelo que concebe a memória com um único sistema amplo com vários elementos em diferentes níveis de ativação. As informações da memória de curto prazo corresponderiam a parcelas da memória de longo prazo com um alto nível de ativação e a memória de trabalho consistiria destes elementos ativados mais os processos de controle da atenção usados para manter o nível de ativação e impedir que outras representações internas ou estímulos externos desviem o foco da atenção levando o conteúdo da memória à desativação.

Rosen e Engle (1997) compararam pessoas com alta e baixa capacidade de memória de trabalho em tarefas de fluência verbal solicitando-as que lembrassem o maior número de animais em um intervalo fixo de tempo. Os autores descobriram que a capacidade de memória de trabalho está ligada à fluência de recuperação. Nesta tarefa as pessoas precisam ativar automaticamente a partir de uma idéia (a categoria "animais") "espalhando" a ativação para idéias da mesma categoria, monitorar-se para não fornecer respostas repetidas, suprimir respostas anteriormente pensadas e gerar "pistas" para a criação de novas idéias. Principalmente os últimos três elemen- 


\section{Ricardo Primi}

tos envolvem o executivo central já que estão ligados a uma busca ativa por informações na memória de longo prazo requerendo um controle ativo da atenção. Os resultados deste estudo indicam que a maior capacidade de memória de trabalho facilita a ativação e fluência de recuperação de informações da memória de longo prazo.

As funções do executivo central recentemente têm sido igualadas à metacogniçạa definida como a avaliação e controle dos processos cognitivos. Shimamura (2000) faz uma revisão das relações entre estes construtos favorecendo a integração de descobertas da neurociência com a psicologia cognitiva. $O$ autor lista quatro funções executivas que se relacionam ao controle metacognitivo: seleção, manutenção, atualização.e redirecionamento de rota (rerouting). A seleção refrere-se à atenção seletiva discutida acima que possibilita ativar certas representações e ao mesmo tempo filtrar outras. A manutenção refere-se à habilidade de manter representações ativas ligada, portanto, ao conceito clássico de memória de curto prazo. A atualização ou manipulação refere-se à adaptação, manipulação ou um novo arranjo das ativações na memória de trabalho. Esta função está ligada ao monitoramento das atividades cognitivas e de seus produtos. A última função o redirecionamento de rota refere-se à troca ou $\mathrm{mu}-$ dança global de uma estratégia cognitiva para outra mais adequada à situação.

\section{As relações entre inteligência fluida, executivo cen- tral e as tarefas de raciocínio analógico}

De modo geral a inteligência. fluida está ligada ao executivo central responsável pelas capacidades resumidas na Tabela 3 sintetizadas a partir dos estudos revisados acima. Elas não devem ser entendidas como funções independentes. De fato alguns autores como Engle e cols. (1999) consideram a capacidade de atenção seletiva como sendo a função básica do executivo central e as outras como subprodutos dela. Já Salthouse e Babcock (1991) consideram três componentes, a eficiência do processamento, capacidade de armazenamento e a capacidade de coordenação. Como parece não haver uma visão consensual sobre as relações entre estas facetas é mais prudente listá-las como funções separadas tendo sempre presente a idéia de interdependência entre elas.
Tabela 3: Síntese das capacidades ligadas ao executivo central

\begin{tabular}{|c|c|}
\hline$\bullet$ & $\begin{array}{l}\text { Capacidade de coordenar atividades mentais } \\
\text { simultâneas. }\end{array}$ \\
\hline & $\begin{array}{l}\text { Capacidade de monitorar e supervisionar a atividade } \\
\text { mental. Capacidade de atualizar ou manipular as } \\
\text { representaçōes na memória de trabalho. }\end{array}$ \\
\hline & $\begin{array}{l}\text { Capacidade de atenção seletiva, isto é, focalizar a } \\
\text { atenção em informações especificas para aumentar suá } \\
\text { ativação e ao mesmo tempo inibir a ativação de outras } \\
\text { informaçōes irrelevantes. }\end{array}$ \\
\hline & $\begin{array}{l}\text { Capacidade de ativação de informações da memórịa de } \\
\text { longo prazo. }\end{array}$ \\
\hline & $\begin{array}{l}\text { Capacidade de redirecionar rotas. Refere-se a troc } \\
\text { mudança global de uma estratégia cognitiva para } \\
\text { mais adequada à situação. }\end{array}$ \\
\hline
\end{tabular}

Como foi discutido a resolução de problemas de raciocínio analógico consiste em uma atividade mental complexa subdividida em um conjunto encadeado de processos básicos chamados componentes. É uma atividade analítica abstrata, pois requer a decomposição do problema em vários processos simples de comparação, coordenados em uma estratégia geral de resolução de problemas (Klauer, 1990). Essa atividade complexa faz uma exigência intensa do central executivo principalmente nas facetas de coordenação e monitoramento de atividades mentais simultâneas, atenção seletiva e redirecionamento de rotas.

A coordenação e monitoramento das atividades mentais que na psicologia cognitiva é geralmente denominada de metacognição ou gerenciameno de metas é um pré-requisito da organização de uma estratégia efetiva de resolução. Como concluíram Carpenter e cols. (1990) comentando sobre o teste Raven: "Uma das principais distinções entre os sujeitos com notas mais altas e os sujeitos com notas baixas foi o sucesso dos primeiros na geração e gestão de metas na memória de curto prazo. Nessa visão, um componente chave da inteligência ạnalítica é o gerenciamento de metas, o processo de criar submetas a partir das metas e o rastreamento da sucessão efetiva (ou não) das submetas, a caminho da sa-. tisfação de metas de níveis mais altos. O gerenciamento de metas torna possível ao sujeito construir formas de conhecimento intermediárias e estáveis a respeito de seu progresso" (p. 428). Por- 
tanto, a resolução de problemas de raciocínio analógico associa-se à organização hierárquica dos passos de resolução, envolvendo inúmeras interações de processos simples de comparação entre estímulos (julgamento de similaridade), implementação dessa atividade, o monitoramento (o que foi feito, o que se está fazendo e o que precisa ser feito) e a revisão, quando necessária.

A capacidade de armazenamento e o gerenciamento de metas estão intimamente relacionados. Possivelmente, a necessidade de uma forma efetiva de gerenciamento de metas seja ditada pela limitação da capacidade de armazenamento, por um lado, e, por outro, pelo enfraquecimento da capacidade de memória devido a efeitos adversos como, por exemplo, a similaridade do conteúdo dos itens a serem armazenados (Baddeley \& Hich, 1994). Nesse sentido, o gerenciamento efetivo de metas, como descrito por Carpenter e cols. (1990), descreve a configuração que as informações adquiridas do problema devem assumir na memória de trabalho, evitando a perda de informação. Carpenter \& cols. mencionam que as metas devem ser organizadas de forma hierárquica e recursiva para que "a falha em uma submeta não coloque em risco submetas prévias que foram realizadas com sucesso" (p. 428).

Outro aspecto importante é a abstração que é basicamente ligada aos processos de controle da atenção ou atenção seletiva. Carpenter e cols. (1990) definem por abstração "construções de representações que são vagamente vinculadas aos inputs perceptuais e que possibilitam generalização em relação ao espaço e o tempo" (p.428). A abstração se expressa possivelmente no momento da construção das regras que relacionam os elementos ou atributos. Em itens com figuras geométricas, um elemento é caracterizado por vários atributos (por exemplo, forma, cor, inclinação, tamanho). Na maioria dos casos, o relacionamento deve ser feito considerando-se um atributo e ignorando outros, por exemplo, quando se têm figuras com formas diferentes, mas cores iguais. Isso corresponde à abstração, uma vez que a semelhança baseia-se apenas em uma parcela da percepção (cor) e não na configuração global (forma + cor). Ela é importante, pois permite considerar semelhanças e diferenças entre os estímulos por meio de conceitos abstratos, e não por meio de aspectos perceptuais concretos.

Pode-se entender a abstraçã̃o como um produto dos processos de atenção seletiva. Como afirma Hunt (1996), "para resolver itens de matrizes, o sujeito deve isolar mudanças progressivas numa dimensão da matriz de figuras, enquanto ignora outras dimensões" (p.4). Em obra mais recente, Hunt (1999) afirma que "as estruturas de controle também asseguram um fluxo organizado de informações para a memória de trabalho, seja do mundo externo ou mesmo da memória, tanto bloqueando informações irrelevantes, quanto descartando aquelas que parecem inúteis para a resolução do problema" (p. 8). O controle da atenção esta intimamente ligado à abstração uma vez que permite o estabelecimento de relações sustentadas em atributos analiticamente segregados das representações globais percebidas.

O terceiro e último aspecto do executivo central ligado a inteligência fluida, a mudança de rotas, é chamado na literatura cognitiva de flexibilidade adaptativa. Bethell-Fox, Lohman e Snow (1984) demonstraram que os problemas de raciocínio analógico com figuras geométricas poderiam ser resolvidos de duas maneiras: uma, pela criação da representação mental completa de uma possível resposta e pela comparação com as alternativas de resposta oferecidas (estratégia de construção/comparação), e outra, pelo ciclo envolvendo a criação/representação mental parcial da resposta, baseado em um único elemento ou atributo, comparação com as alternativas, eliminação das alternativas inconsistentes e reinício do ciclo com um segundo atributo (estratégia de eliminação de respostas). Essas duas maneiras são chamadas estratégias de resolução, pois compreendem combinações específicas de componentes de solução. Bethell-Fox et al. (1984) demonstraram também que a estratégia construção/comparação é usada mais freqüentemente por sujeitos com alta habilidade e em itens simples. A estratégia de eliminação de respostas é mais utilizada por sujeitos com baixa habilidade e em itens complexos.

Portanto, a flexibilidade adaptativa refere-se à seleção, uso e alteração de estratégias de resolução diante das demandas impostas pelos problemas. Bethell-Fox e cols. (1984) relacionaram essas descobertas às demandas que itens complexos fazem à memória de trabalho, sugerindo; portanto, que sujei- 


\section{Ricardo Primi}

tos com baixa habilidade utilizam a estratégia de eliminações de respostas pois experimentam, com mais facilidade, a sobrecarga da memória de trabalho.

\section{Evidências da Neurociência e da Neuropsicologia}

No final da década de noventa começaram a aparecer alguns estudos empregando a neuroimagem identificando a localização das estruturas cerebrais ligadas à memória de trabalho e à inteligência fluida. Dois estudos são de grande importância para o assunto tratado neste artigo: o de Smith e Jonides (1997) e o de Prabhakaran, Smith, Desmond, Glover \& Gabrieli (1997).

Smith e Jonides (1997) estudaram quais áreas cerebrais eram ativadas enquanto os participantes executavam um variado número tarefas de memória de trabalho por meio da Tomografia por Emissão de Pósitrons (PET) reafirmando o modelo de memória de Baddeley e Hitch (1994) e detalhando-o mais. Os autores encontraram estruturas distintas para a memória verbal, visual e espacial. A memória verbal (ciclo fonológico) e a memória visual para objetos estão localizadas na porção parietal posterior do hemisfério esquerdo. A memória espacial (área de armazenamento visual) está localizada na região parietal posterior do hemisfério direito. Há também uma diferença entre processos de armazenamento e reativação pela repetição (rehearsal) sendo que na memória verbal o armazenamento ocorre na porção posterior parietal e a reativação nas regiões frontais do hemisfério esquerdo (área de Broca, área prémotor e área motor suplementar). Na memória espacial há a mesma distinção com as mesmas áreas envolvidas só que localizadas no hemisfério direito. $\mathrm{O}$ executivo central é mediado pelo córtex pré-frontal dorsolateral. Uma fato interessante é que há um grande número de estudos testando variadas funções executivas tais como monitoramento, mudança de estratégia, coordenação simultânea de atividades evidenciando sempre o envolvimento da área pré-frontal dorsolateral. Estes resultados corroboram a ligação entre o central executivo; metacognição e fator $g$.

Prabhakaran e cols. (1997) mapearam as áreas cerebrais ativadas enquanto as pessoas resolviam itens do Raven empregando a Ressonância Magnética Funcional (fMRI). Os autores escolheram itens de forma sistemática permitindo distinguir quais áreas cerebrais eram recrutadas enquanto os sujeitos resolviam problemas requerendo processos perceptuais simples de raciocínio, problemas analíticos e problemas de comparação perceptual (tarefa controle). Os resultados indicaram que nos problemas perceptuais foi ativada a área frontal do hemisfério direito e as regiões parietais bilateralmente. Nos problemas analíticos foram ativadas as áreas parietal, occipital, temporal esquerdas e as áreas frontais bilateralmente. Os resultados indicaram que os problemas perceptuais ativavam áreas mediadores da memória de trabalho visual-espacial e os problemas analíticos recrutavam estas e outras ares mediadores de memória verbal e de processos executivos.

Além destes estudos existem vários estudos neuropsicológicos os quais aplicam medidas cognitivas em pacientes com lesões conhecidas em regiões específicas do cérebro buscando verificar qual habilidade é afetada em decorrência das lesões. Estes estudos têm relacionado os processos do executivo central à região frontal do cérebro (Baddeley, 1996a; Shimamura, 2000). Nesta linha Duncan, Emslie e Williams (1996) encontraram especificamente correlações entre lesões frontais e dificuldades em tarefas de inteligência fluida.

\section{Conclusão}

Em síntese, os estudos revisados acima oferecem evidências muito sólidas sobre a concepção da memória de trabalho (seus componentes e funções) e da sua relação com a inteligência fluida especialmente com o executivo central. Eles mostram que as covariâncias comportamentais demonstradas nos estudos psicométricos começam a ser consubstanciadas e elaboradas em mais detalhes nas estruturas cerebrais identificadas pelos estudos recentes da neurociência.

Fazendo uma relação entre estes estudos e os modelos psicométricos pode-se entender que quatro fatores do modelo CHC inteligência fluida $(G f)$, memória de curto prazo (Gsm), armazenamento e recuperação da memória de longo prazo $(G l r)$ e processamento visual $(G v)$ estão ligados às fụnções do executivo central. De fato Woodcock $(1997,1998)$ agrupa os dez fatores em quatro clusters sendo que 
um deles chama-se habilidades de pensamento e inclui os fatores $G f, G v, G l r$ e $G a$ (processamento auditivo). Estas relações entre habilidades mais complexas são coerentes com a noção do fator $g$ materializado terceiro estrato do modelo de Carroll (1993). Neste sentido a operação cognitiva geral subjacente ao $g$ que tem sido relacionada ao executivo central (Badeley, 1996a, p. 7) pode ser resumida nas sete funções apresentadas na Tabela 3.

Há também um amplo conjunto de evidências que apóiam a validade de construto de tarefas de raciocínio analógico para a mensuração de funções do executivo central. Neste sentido novos instrumentos com uma definição mais clara sobre o que avaliam poderão ser criados por intermédio da aplicação do conhecimento acumulado pela psicologia cognitiva e da neurociência discutido aqui. A expectativa é que estas novas medidas sejam de melhor qualidade pois serão construídas para medir aspectos mais claramente delimitados das funções cognitivas.

\section{Referências Bibliográficas}

Almeida, L.S. (1988). Teorias da Inteligência. Porto: Edições Jornal de Psicologia.

Almeida, L.S. (1994) Inteligência: Definição e Medida. Aveiro: CIDInE.

Baddeley, A.D. (1996a). Exploring the central executive. The Quarterly Journal of Experimental Psychology, 49A(1), 5-28.

Baddeley, A.D. (1996b). The fractionation of working memory. Proc. Natl. Acad. Sci., 93, 13468-13472.

Baddeley, A.D. (1998). Recent developments in working memory. Current opinion in neurobiology, 8, 234-238.

Baddeley, A.D. \& Hich, G.J. (1994). Developments in the concept of working memory. Neuropsychology, 8 (4), 485-493.

Bethell-Fox, C.E., Lohman, D.F. \& Snow, R.E. (1984). Adaptive reasoning: componential and eye movement analysis of geometric analogy performance. Intelligence, 8, 205-238.

Carpenter, P.A., Just, M.A., \& Shell, P. (1990). What one intelligence test measures: a theoretical account of the processing in the Raven
Progressive Matrices test. Psychological Review, 97 (3), 404-431.

Carroll, J.B. (1993). Human cognitive abilities: a survey of factor-analytic studies. New York: Cambridge University Press.

Cattell, R.B. (1941). Some theoretical issues in adult intelligence testing. Psychological Bulletin, 31, 161-179.

Cattell, R. B. (1971). Abilities: Their structure, growth and action. Boston: Houghton Mifflin.

Daneman, M. \& Carpenter, P.A. (1980). Individual differences in working memory and reading. Journal of Learning and Verbal Behaviour, 19, 450-466.

Duncan, J., Emslie, H. \& Williams, P. (1996). Intelligence and the frontal lobe: the organization of goal-directed behavior. Cognitive Psychology, 30, 257-303.

Embretson, S. (1994). Applications of cognitive design systems to test development. Em: C. R. Reynolds. (Ed.), Cognitive assessment: a multidisciplinary perspective. New York: Plenum Press.

Embretson, S. (1995). The role of working memory capacity and general control process in intelligence. Intelligence, 20, 169-189.

Embretson, S. (1998). A cognitive design system approach to generating valid tests: application to abstract reasoning. Psychological Methods, 3 (3), 380-396.

Engle, R.W., Tuholski, S.W., Laughlin, J.E., \& Conway, A.R.A. (1999). Working memory, short-term memory, and general fluid. intelligence: a latent-variable approach. Journal of Experimental Psychology: General, 128 (3), 309-331.

Evans, T.G. (1968). Program for the solution of a class of geometric-analogy intelligent-test questions. Em: M. Minsky (Ed.), Semantic information processing. Cambridge: MIT Press.

Flanagan, D.P., McGrew, K.S. \& Ortiz, S.O. (2000). The Wechsler Intelligence Scales and Gf-Gc Theory: a contemporary approach to interpretation. Boston: Allyn \& Bacon.

Flanagan, D.P. \& Ortiz, S.O. (2001). Essentials of 


\section{Ricardo Primi}

cross-battery assessment. New York: John Wiley \& Sons, Inc.

Goldman, S.R. \& Pellegrino, J.W. (1984). Deductions about induction: analyses of developmental and individual differences. In R. J. Sternberg (Ed.), Advances in the psychology of human intelligence, Vol. 2. Hillsdale: Lawrence Eribaum Associates.

Gonzales Labra, M.J. (1990). El nivel de abstracción en las analogias geométricas. Revista de Psicologia General y Aplicada, 43 (1), 23-32.

Gonzales Labra, M.J. \& Ballesteros Jimenez, S. (1993) Análisis componencial de las analogías geométricas. Revista de Psicologia General y Aplicada, 46 (2), 139-147.

Green, K.E. \& Kluever, R.C. (1992) Components of item difficulty of Raven's matrices. Journal of General Psychology, 119 (2), 189-199.

Horn, J.H. (1991). Measurement of intellectual capabilities: a review of theory. In: K. S. McGrew, J. K. Werder, \& R. W. Woodcock (Eds.), WJ-R Technical Manual. Allen: DLM.

Horn, J.L. \& Cattell, R.B. (1966) Refinement and test of the theory of fluid and crystalized general intelligences: Journal of Educational Psychology, 57(5), 253-270.

Horn, J.L. \& Noll, J. (1997) Human cognitive capabilities: Gf-Gc theory. Em: Flanagan, D. P., Genshaft, J. L. \& Harrison, P. L. (Eds.) Contemporary intellectual assessment: theories, tests, and issues. (pp. 53-91). New York: The Guilford Press.

Hornke, L.F. \& Habon, M.W. (1986). Rule-based item bank construction and evaluation within the linear logistic framework. Applied Psychological Measurement, 10 (4), 369-380.

Hunt, E. (1996). Intelligence for the 21st Century. Manuscrito da apresentação na conferência da European Society for Cognitive Psychology e Spanish Society for the Study of Individual Differences, Madrid.

Hunt, E. (1999). Intelligence and human resources: past, present and future. In: P. L. Ackerman, P. C. Kyllonen, \& R. D. Roberts (Eds.), Learning and individual differences: process, trait and content determinants. Washington, DC: American Psychological Association.

Jurden, F.H. (1995). Individual differences in working memory and complex cognition. Journal of Edücational Psychology, 87 (1), 93102.

Kane, M.J., Bleckley, M.K. Conway, A.R.A. \& Engle, R.W. (2001). A controlled-attention view of working-memory capacity. Journal of Experimental Psychology: General, 130(2), 169-183.

Klauer, K.J. (1990). A process theory of inductive reasoning tested by teaching of domain-specific thinking strategies. European Journal of Psychology of Education, 5 (2): 191-206.

Kyllonen, P.C. \& Cristal, R. (1990). Reasoning ability is (little more than) working memory capacity?! Intelligence, 14, 389-434.

McGrew, K.S. \& Flanagan, D.P. (1998). The intelligence test desk reference (ITDR): $G f-G c$ cross-battery assessment. Needham Heihts: Allyn \& Bacon.

Miyake, A., Friedman, N.P., Rettinger, D.A., Shah, P. \& Hegarty, M. (2001). How are Visuospatial Working Memory, Executive Functioning, and Spatial Abilities Related? A Latent-Variable Analysis. Journal of Experimental Psychology: General, 130 (4), 621-640.

Mulholland, T.M., Pellegrino, J.W., \& Glaser, R. (1980). Components of geometric analogy solution. Cognitive Psychology, 12, 252-284.

Pellegrino, J.W. \& Glaser, R. (1979). Cognitive correlates and components in the analysis of individual differences. Intelligence, 3, 187-214.

Pellegrino, J.W. \& Lyon, D.R. (1979). The components of a componential analysis. Intelligence, 3, 169-186.

Posner, M.I. \& DiGirolamo, G.J (2000). Cognitive neuroscience: Origins and promise. Psychological Bulletin., 126(6), 873-889.

Prabhakaran, V., Smith, J.A.L., Desmond, J.E., Glover, G.H., \& Gabrieli, J.D.E. (1997). Neural substances of fluid reasoning: an fMRI study of neocortical activation during performance of the Raven's Progressive Matrices test. Cognitive Psychology, 33, 43-63. 
Primi, R. (1995) Inteligência, processamento de informação e teoria da gestalt: um estudo experimental. Dissertação de Mestrado. Pontifícia Universidade Católica de Campinas.

Primi, R. (1998). Desenvolvimento de um instrumento informatizado para avaliação do raciocínio analitico. Tese de Doutorado. Instituto de Psicologia, Universidade de São Paulo.

Primi, R. (2002) Complexity of Geometric Inductive Reasoning Tasks: Contribution to the Understanding of the Fluid Intelligence. Intelligence, 30 (1), 41-70.

Primi, R. \& Rosado, E.M.S. (1995) Os princípios de organização perceptual e a atividade inteligente: um estudo sobre testes de inteligência. Estudos de Psicologia, 11 (2), 3-12.

Primi, R., Rosado, E.M.S., \& Almeida, L.S. (1995). Resolução de tarefas de raciocínio analógico: contributos da teoria da gestalt à compreensão dos problemas subjacentes. In L. S. Almeida, \& Ribeiro, I. S. (Eds.), Avaliação Psicológica: Formas e Contextos, Vol. 3. Braga: APPORT (Associação dos Psicólogos Portugueses).

Raven, J.C. (1962) Matrizes Progressivas - Escala Avançada - Série I e II. Rio de Janeiro: CEPA

Raven, J., Raven J.C. \& Court, J.H. (1998). Manual for Raven's progressive matrices and vocabulary scales: section 1 general overview. Oxford: Oxford Psychologysts Press.

Rosen, V.M. \& Engle, R.W. (1997). The role of working memory capacity in retrieval. Journal of Experimental Psychology: General, 126(3), 211-227.

Rumelhart, D.E. \& Abrahamson A.A. (1973). A model for analogical reasoning. Cognitive Psychology, 5, 1-28.

Salthouse, T.A. \& Babcock, R. L. (1991). Decomposing adult age differences in working memory. Developmental Psychology, 27(5), 763776.

Shimamura, A P. (2000). Toward a cognitive neuroscience of metacognition. Consciousness and Cognition, 9, 313-323.

Smith, E. \& Jonides, J. (1997). Working memory: a view from neuroimaging. Cognitive Psychology,
33, 5-42.

Snow, R. Kyllonen, P. \& Marshalek (1984) The Topography of ability and learning correlations. Em: R.J. Sternberg (Ed.), Advances in the psychology of human intelligence (pp. 47-103). Vol. 2. Hillsdale: Lawrence Erlbaum Associates.

Spearman, C. (1927). The abilities of man: Their nature and measurement. New York: Macmillan.

Sternberg, R J. (1977). A component process in analogical reasoning. Psychological Review, 84, 4, 353-378.

Sternberg, R.J. (1979). The nature of mental abilities. American Psychologist, 34, 3, 214-230.

Sternberg, R.J. (1980). Factor theories of intelligence are all right almost. Educational Researcher, 9, 6-13.

Stemberg, R.J. (1981). The evolution of theories of intelligence. Intelligence, 5, 209-230.

Sternberg, R.J., \& Gardner, M. K. (1983). Unities in inductive reasoaning. Journal of Experimental Psychology General, 112, 80-116.

Woodcock, R.W. (1997). The Woodcock-Johnson Tests of Cognitive Ability - revised. Em: D.P. Flanagan, J. Genshaft \& P.L. Harrison (Eds.). Contemporary intellectual assessment: Theories, tests and issues (pp. 230-246). New York: Guilford.

Woodcock, R.W. (1998). Extending GF-GC theory into practice. Em: J.J. McArdle \& R.W. Woodcock, (Eds.). Human cognitive abilities in theory and practice (pp. 137-156). Mahwah: Erlbaum. 